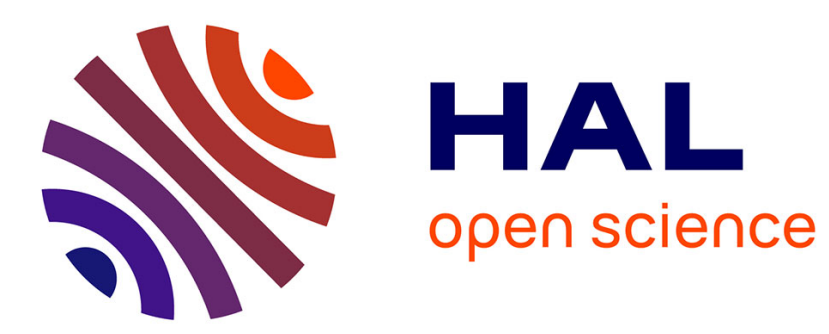

\title{
A Simulation Tool For Brassiness Studies, Preliminary Results Obtained From Brass Instrument's Bores
}

\author{
Joël Gilbert, Ludovic Menguy, Murray Campbell
}

\section{To cite this version:}

Joël Gilbert, Ludovic Menguy, Murray Campbell. A Simulation Tool For Brassiness Studies, Preliminary Results Obtained From Brass Instrument's Bores. International Symposium of Nonlinear Acoustic (18th ISNA), Jul 2008, Stockholm, Sweden. hal-00475552

\section{HAL Id: hal-00475552 \\ https://hal.science/hal-00475552}

Submitted on 22 Apr 2010

HAL is a multi-disciplinary open access archive for the deposit and dissemination of scientific research documents, whether they are published or not. The documents may come from teaching and research institutions in France or abroad, or from public or private research centers.
L'archive ouverte pluridisciplinaire HAL, est destinée au dépôt et à la diffusion de documents scientifiques de niveau recherche, publiés ou non, émanant des établissements d'enseignement et de recherche français ou étrangers, des laboratoires publics ou privés. 


\title{
A Simulation Tool For Brassiness Studies, Preliminary Results Obtained From Brass Instrument's Bores
}

\author{
J. Gilbert ${ }^{\mathrm{a}}$, L. Menguy ${ }^{\mathrm{a}}$ D.M.Campbell ${ }^{\mathrm{b}}$ \\ ${ }^{a}$ Laboratoire d'Acoustique de l'Université du Maine, CNRS, Le Mans, France, \\ joel.gilbert@univ-lemans.fr,ludovic.menguy@wanadoo.fr \\ ${ }^{b}$ University of Edinburgh, Edinburgh EH9 3JZ, UK, \\ M.Campbell@ed.ac.uk
}

\begin{abstract}
The brightness of the sound generated by brass instruments at high dynamic level is mainly due to the essential nonlinearity of the wave propagation in the pipe. The bright instruments such as the trumpet and the trombone (high brassiness) are different from more mellow brass instruments such as saxhorns or flugelhorns (low brassiness). The bright instruments have an almost cylindrical pipe segment just downstream of the mouthpiece. The conical bore of the saxhorns in this region implies a faster decay of the wave which reduces the nonlinear wave steepening. To investigate the differences between the brassiness of different instruments, crescendos have to be played (experiments) or simulated (theory). Then a spectral enrichment parameter, characterising the rate of spectral enrichment with increasing dynamic level, can be extracted for each instrument. A frequency-domain numerical model of brass instrument sound production is proposed as a tool to predict the spectral enrichment parameter (brassiness characterisation). It is based on generalized Burger's equations applied to weakly nonlinear wave propagation in non uniform ducts. The relevance of the present tool is evaluated by doing simulations of periodic regimes using typical brass instrument's bores, from which the spectral enrichment parameters are calculated, and compared to measured ones.
\end{abstract}

Keywords: acoustics, nonlinear propagation, brass instruments, simulation.

PACS: $43.75 . \mathrm{Fg}$ and $43.25 . \mathrm{Gf}$

\section{INTRODUCTION}

The brightness of the sound generated by brass instruments at high dynamic level is mainly due to the essential nonlinearity of the wave propagation in the pipe [1]. The bright instruments such as the trumpet and the trombone (high brassiness) are different from more mellow brass instruments such as saxhorns or flugelhorns (low brassiness). The bright instruments have an almost cylindrical pipe segment just downstream of the mouthpiece. The conical bore of the saxhorns in this region implies a faster decay of the wave which reduces the nonlinear wave steepening.

To investigate the differences between the brassiness of different instruments, crescendos have to be played. Then a spectral enrichment parameter, characterising the rate of spectral enrichment with increasing dynamic level, can be extracted for 
each instrument played. A complementary approach to the experimental approach, is to use a simulation tool in order to estimate the spectral enrichment parameter, knowing the bore profiles of the brass instruments investigated. The aim of the present paper is to test the relevance of the simulation tool presented in [2]. It is evaluated by doing simulations of periodic regimes using typical brass instrument bores, from which the spectral enrichment parameters are calculated, and compared to measured ones already published in [3]. After this introduction, the simulation tool and its theoretical context presented in details in [2] are briefly summarised. Then preliminary simulated spectral enrichment parameter results are compared to measured ones.

\section{THEORETICAL BACKGROUND AND SIMULATION TOOL}

The theoretical background is weakly nonlinear acoustic propagation in nonuniform ducts [4]. The study of weakly nonlinear propagation in a dissipative viscothermal homogeneous fluid assuming a one-dimensional flow in a nonuniform duct leads to first-order nonlinear differential twin equations using the dimensionless variables $\sigma$ (a slow geometric scale equal to $(\gamma+1) / 2 . M . x$ where $\gamma$ is the specific heat ratio, $M$ a Mach number, $\mathrm{x}$ a dimensionless geometric scale), $\theta_{+}$and $\theta_{-}$(dimensionless

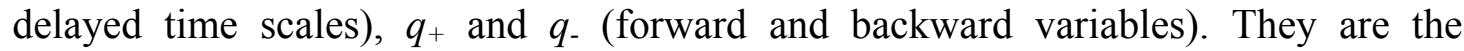
"generalized Burgers equations" for the forward-traveling wave, Eq. 1, and for the backward-traveling wave, Eq. 2:

$$
\begin{aligned}
& \frac{\partial q_{+}}{\partial \sigma}-q_{+} \frac{\partial q_{+}}{\partial \theta_{+}}+q_{+} \frac{\partial \ln (R(\sigma) / R(0))}{\partial \sigma}=+\frac{1}{\Gamma} \frac{\partial^{2} q_{+}}{\partial \theta_{+}^{2}}-\frac{T}{\varepsilon} \frac{\partial^{1 / 2} q_{+}}{\partial \theta_{+}^{1 / 2}} \\
& \frac{\partial q_{-}}{\partial \sigma}+q_{-} \frac{\partial q_{-}}{\partial \theta_{-}}-q_{-} \frac{\partial \ln (R(\sigma) / R(0))}{\partial \sigma}=-\frac{1}{\Gamma} \frac{\partial^{2} q_{-}}{\partial \theta_{-}^{2}}+\frac{T}{\varepsilon} \frac{\partial^{1 / 2} q_{-}}{\partial \theta_{-}^{1 / 2}}
\end{aligned}
$$

where $\Gamma$, the Gold'berg number, is a measure of the importance of effects of volume dissipation compared to those of nonlinearity. A plane wave that propagates in a duct with rigid walls experiences dispersion and attenuation as a result of the viscothermal boundary layer along the walls. As a consequence, the right hand side of Eq. 1 and 2 contains a second term controlled by the dimensionless number $T / \varepsilon$ [5] which is a measure of the strength of nonlinearity relative to that of wall dissipation. If the volume viscothermal effects - controlled by $\Gamma$ - are frequency squared dependent, the classical dependence of the viscothermal boundary-layer losses - controlled by $T / \varepsilon-$ is on the square root of the frequency. The left hand of Eq. 1 and 2 exhibits a term which is a function of the interior radius $R(x)$ of the nonuniform duct, characterizing its slowly varying cross section.

The spectral enrichment can be evaluated from the radiated pressure spectral centroid SC estimation during a crescendo. In expanding bores, a faster decay of the wave amplitude reduces the nonlinear steepening effect: this provides a hypothesis to explain the fact that "conical" instruments are not as brassy as "cylindrical" instruments. More precisely, the brassiness of two brass instruments, or of two fingerings or positions of a given instrument, can be compared from their spectral centroid values for a given crescendo [3]. The comparison can also be made by 
simulation, the input data being the internal geometry of the instrument, its bore, and typical acoustical pressures at the input end of the instrument.

The frequency model simulation method is based on the previous publications of [5] and [2], dedicated to uniform and non uniform ducts respectively. The simulation can be summarized as follows: postulating the pressure spectrum $P_{i n}$ at the input end, a radiated impedance boundary condition at the output end, and the bore geometry of the instrument, the pressure and velocity acoustic field are first calculated everywhere inside the bore using the weakly nonlinear approximation. Indeed the simple waves propagating in each direction are supposed not to interact in the body of the fluid as in the linear approximation, and they are solutions of the nonlinear differential Eq. 1 and 2. The details of the numerical method and a harmonic balance convergence method are given in the above references. The volume velocity spectrum $Q_{o u t}$ at the output end of the instrument is estimated by multiplying the output area by the output acoustic velocity spectrum. By using the low-frequency approximation for a monopole having a volume strength equal to $Q_{o u t}$, a radiated pressure spectrum $P_{\text {rad }}$ and its spectral centroid $S C_{\text {rad }}$ are estimated at a distance $d$ from the open end of the pipe from Eq. 3:

$$
p_{\text {rad }}=\frac{\rho}{4 \pi d} j \omega Q_{\text {out }}
$$

\section{COMPARISON BETWEEN SIMULATIONS AND EXPERIMENTS: PRELIMINARY RESULTS}

A set of five brass instruments (Figure 1, left) have been played several times by three brass players, by doing crescendos from pianissimo to fortissimo levels. The spectral centroids $\mathrm{SC}_{1}$ and $\mathrm{SC}_{2}$ corresponding to the recorded pressure signals of the internal pressure in the mouthpiece (channel 1) and the radiated pressure (channel 2), have been processed. At the end of processing the data, we were looking for a single value characterising the spectral enrichment. This value, called $A_{1}$, is extracted from a fit of the spectral centroid ratio $S C_{2} / S C_{1}$ function of $P_{1} r m s$. The fit is based on the empirically chosen function $y=f(x)$ characterised by two coefficients $A_{1}$ and $A_{2}$ as follows in Eq. 4:

$$
y=f(x)=A_{2}\left[\exp \left(A_{1} x\right)-\left(A_{1} x\right)\right] .
$$

The spectral enrichment values $\mathrm{A}_{1}$ obtained from experiments are displayed (Figure 1 , right) as a function of the brassiness parameter $\mathrm{B}$. The dimensionless parameter $\mathrm{B}$ is calculated from the bore shape of each brass instrument using a coordinate stretching function (for details, see [3]). The "cylindrical" brass instruments are associated with high values of $B$, and "conical" ones whit low values of $B$. The spectral enrichment parameter $A_{1}$ coming from experiment has been found to be a monotonic increasing function of the brassiness parameter $B$.

From the bores of three of the five brass instruments (ophicleïde, bass saxhorn, bass trombone), spectral enrichment $A_{1}$ values have been obtained by doing simulations. These are also shown in Fig 1 (right). It can be seen that the monotonic behaviour of simulated $A_{1}$ as a function of $B$ is maintained, the numeric values being in the range of the ones coming from experiments. 

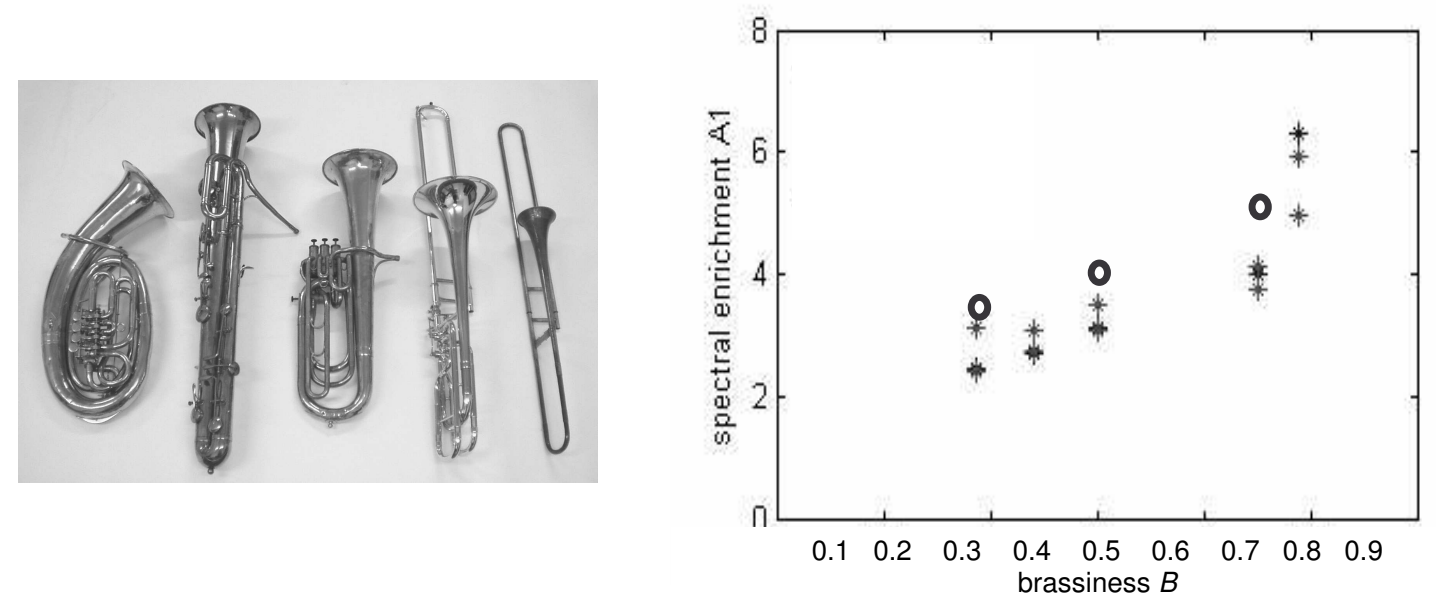

FIGURE 1. (adapted from [3])

Left: the five brass instruments are tenor and bass trombone, bass saxhorn, ophicleïde and kaiserbaryton (from right to left), their brassiness values B being from 0.31 (ophicleïde) to 0.81 (tenor trombone).

Right: the values of $A_{1}$ as a function of $B$, results corresponding to three brass players (*) playing the five brass instruments (tenor and bass trombone, bass saxhorn, kaiserbaryton and ophicleïde, corresponding to decreasing B values), and to simulated results (o) associated to three of the five.

It must be borne in mind that the brassiness parameter $\mathrm{B}$ is derived from a simplified theory of weakly nonlinear propagation which considers only lossless propagation in the forward direction. Nevertheless the simulation tool briefly presented and used in the present paper might be a useful tool to establish the reliability of the parameter $\mathrm{B}$ as a predictor of the ease with which an instrument generates "cuivrés" or brassy sounds. It could also be useful in assessing the perceptual significance of non-linear propagation at playing levels well below the "brassy" regime.

\section{ACKNOWLEDGMENTS}

Arnold Myers is thanked for measurements of the bore profiles, and more generally for helpful discussion dealing with the brass instruments and the brassiness project.

\section{REFERENCES}

1 Hirschberg, A.; Gilbert, J.; Msallam, R.; Wijnands, A.P.J. (1996). "Shock waves in trombones," J. Acoust. Soc. Am. 99, pp.1754-1758

2 Gilbert, J.; Menguy, L.; Campbell, D.M. (2008), "A simulation tool for brassiness studies”, accepted for publication in J. Acoust. Soc. Am.

3 Gilbert, J.; Campbell, D.M; Myers, A.; Pyle, R.W.; (2007). "Differences between brass instruments arising from variations in brassiness due to nonlinear propagation," Proceedings of International Symposium in Musical Acoustics, Barcelona

4 Hamilton, M.F.; Blackstock, D.T. (eds) (1998). Nonlinear Acousics, Academic Press

5 Menguy, L.; Gilbert, J. (2000), "Weakly non-linear gas oscillations in air-filled tubes ; solutions and experiments", Acta Acustica united with Acustica 86, pp. 798-810 